\title{
Effective multi-functional biotechnological applications of protease/keratinase enzyme produced by new Egyptian isolate (Laceyella sacchari YNDH)
}

\author{
Doaa A. Goda', Ahmad R. Bassiouny², Nihad M. Abdel Monem², Nadia A. Soliman ${ }^{1 *}$ and Yasser R. Abdel Fattah
}

\begin{abstract}
Background: Due to a multitude of industrial applications of keratinolytic proteases, their demands are increasing. The present investigation studied the production and monitoring of the most possible multi-functional applications of YNDH thermoalkaline keratin-degrading enzyme.

Results: This work is considered the first that reported YNDH strain closely related to Laceyella sacchari strain; YNDH is a producer of protease/keratinase enzyme and able to degrade natural keratin such as feathers, wool, human hairs, and nails. Experimental design Plackett-Burman (PBD) was applied to evaluate culture conditions affecting the production of thermoalkaline protease/keratinase. Afterwards, Box-Behnken design (BBD) was applied to find out the optimum level of significant variables namely, $\mathrm{NH}_{4} \mathrm{Cl}$, yeast extract, and $\mathrm{NaNO} 3$ with a predicted activity of $1324.7 \mathrm{U} / \mathrm{ml}$. Accordingly, the following medium composition and parameters were calculated to be optimum (\%w/ v): $\mathrm{NH} 4 \mathrm{Cl}, 0.08$; feather, 1 ; yeast extract, $0.04 ; \mathrm{MgSO}_{4} .7 \mathrm{H}_{2} \mathrm{O}, 0.02 ; \mathrm{NaNO}_{3}, 0.016 ; \mathrm{KH}_{2} \mathrm{PO}_{4}, 0.01 ; \mathrm{K}_{2} \mathrm{HPO}_{4}, 0.01 ; \mathrm{pH}, 8$; inoculum size; $5 \%$, cultivation temperature (Temp.) $45^{\circ} \mathrm{C}$ and incubation time $48 \mathrm{~h}$. The studied enzyme can degrade keratin-azure, remove proteinaceous materials, and is able to remove hairs from goat hides. These interesting characteristics make this enzyme a good candidate in many applications especially in detergent (Det.), in leather industries, and in pharmaceuticals particularly in nail treatment.

Conclusion: The promising properties of the newly keratin-degrading protease enzyme from Laceyella sacchari strain YNDH would underpin its efficient exploitation in several industries to cope with the demands of worldwide enzyme markets.
\end{abstract}

Keywords: Protease, Keratinolytic activity, Experimental design, Laceyella sacchari YNDH

\section{Background}

Keratinolytic proteases (E.C 3.4.21/24/99.11) have substrate specificity where they have the ability to hydrolyze soluble protein such as casein, gelatin, and bovine serum albumin. In recent years, the demands of keratinolytic

\footnotetext{
* Correspondence: nadiastuttgart@yahoo.com

'Bioprocess Development Department, Genetic Engineering and

Biotechnology Research Institute (GEBRI), City of Scientific Research and Technological Applications (SRTA-City), New Burg El-Arab City, Universities and Research Institutes Zone, Alexandria Post 21934, Egypt

Full list of author information is available at the end of the article
}

proteases are increasing due to their multitude in industrial applications such as the fertilizer, detergent (Det.), and textile industries [1]. For mature chickens, feathers account for up to $5 \%$ to $7 \%$ of their weight and are composed of over $90 \%$ crude protein, the main components being keratin and insoluble protein [2]. At present, feathers are converted to feather meal, a digestible dietary protein for animals, using physical and chemical treatments. These physicochemical conversion methods involve costly treatments under high-temperature (Temp.) and -pressure conditions in addition to the fact 
that the high Temp. causes the loss of a certain number of amino acids such as methionine, lysine, and tryptophan. Conventional disposal methods such as incineration of feathers have ecological disadvantages. Nowadays, feathers are converted into feather meal and used as animal feed supplement $[3,4]$. However, the methods currently used for the conversion of feathers hydrolysis are chemical (alkaline hydrolysis) and the physical (steam pressure cooking); these methods, apart from being ecologically unfriendly and expensive due to the energetic cost, cause the loss of nutritionally essential amino acids [3-7].

Bacterial keratinolytic enzymes can have significant uses in biotechnological procedures involving keratincontaining waste from poultry and leather industries by developing non-polluting procedures. Insoluble feather keratins can be transformed to feature meal, fertilizers, and glues after enzymatic hydrolysis or used to produce rare serine, cysteine amino acids $[3,4,8]$. The elevated price of enzyme manufacturing is one of the main disadvantages faced by industrial enzyme manufacturers, as $30-40 \%$ of the manufacturing costs of many industrial enzymes are attributable to the price of the medium of cultivation [9]. For several centuries, statistical experimental designs have been used and can be implemented at different stages of an optimization strategy, such as screening tests or searching for ideal circumstances for targeted response(s) [10]. Recently, the findings evaluated through a statistically scheduled experiment are better recognized than the outcomes of the traditional one-variable-at-a-time (OVAT) test. The PlackettBurman design (PBD) and response surface designs (RSD) are some of the common options when applying statistical models to bioprocessing [11-14]. The primary purpose of this research is to assess the circumstances of culture that affect the output of thermoalkaline protease with keratinolytic activity by locally isolated Laceyella sacchari YNDH and the possible application of this enzyme. In this way, the theme chosen for the application research can be exploited in many industries such as the leather industry, feeding, medical, and others.

\section{Methods}

\section{Bacterial isolation}

Samples were collected from different localities in Egypt (El-Minya governorate, Wadi El-Natrun lake, Hammam Pharaon) and Indonesia. For bacterial isolation, three different media were used, namely alkaline nutrient medium for Indonesian and El-Minya samples at $37^{\circ} \mathrm{C}$, $\mathrm{pH} 10.0$ for $24 \mathrm{~h}$, Haloalkalophilic medium for Wadi ElNatrun samples at $45^{\circ} \mathrm{C}$, pH 9.5 for $48 \mathrm{~h}$ and Luria-Bertani liquid medium (LB), for Hammam Pharaon samples at $55-70^{\circ} \mathrm{C}, \mathrm{pH} 7$ for $24 \mathrm{~h}$. After the cultivation time, 1 $\mathrm{ml}$ from each flask serially was diluted, and then about $100 \mu \mathrm{l}$ of $10^{-3}$ and $10^{-8}$ dilutions were spread on Petri dishes and kept under the same isolation-cultural conditions for purification. The pure separate colonies were maintained on slants at $4{ }^{\circ} \mathrm{C}$, and then sub-cultured regularly.

\section{Qualitative screening for protease activity}

The qualitative screening was carried out using the same isolation medium but supplemented with $1 \%$ gelatin/casein as a substrate. The cultured plates were incubated for $24 \mathrm{~h}$ each at its own specific Temp. The appearance of a clear transparent zone was indicative for hydrolysis of the substrate by an extra-cellular protease. The hydrolysis of the tested substrate was developed by overlaying the plates with $15 \%(\mathrm{w} / \mathrm{v}) \mathrm{HgCl}_{2}$ in $20 \% \mathrm{HCl}$ [15]. The diameter of the clear zone was considered a semiquantitative estimation of protease activity.

\section{Qualitative screening for keratinase activity}

Keratinase activity of each isolate was tested individually by growing in a selective medium with the following composition (g/L): $\mathrm{NH}_{4} \mathrm{Cl} 0.5, \mathrm{NaCl} 0.5, \mathrm{KH}_{2} \mathrm{PO}_{4} 0.4$, $\mathrm{K}_{2} \mathrm{HPO}_{4} 0.3, \mathrm{MgCl}_{2} \cdot 6 \mathrm{H}_{2} \mathrm{O} 0.1$ containing $1 \%(\mathrm{w} / \mathrm{v})$ feather, under the previously used conditions (Temp. and $\mathrm{pH})$. The degradation of feathers is indicative for hydrolysis of the substrate by an extra-cellular keratinase.

\section{Effect of $\mathrm{pH}$ and Temp. on the growth and enzyme activity}

In this experiment, the growth of the selected YNDH strain was evaluated with respect to variation in $\mathrm{pH}$ (7$10.5)$ and Temp. $\left(37-60^{\circ} \mathrm{C}\right)$, using dry weight/OD as a measurable indicator for growth. Also, $\mathrm{pH}$ variation (710.5) and Temp. $\left(37-70^{\circ} \mathrm{C}\right)$ were tested in order to find the optimal for enzyme activity.

\section{Quantitative estimation of protease activity}

Protease activity was measured by the method of Kembhavi and Kulkarni [16] using 1\% casein as a substrate at pH $10\left(100 \mathrm{mM}\right.$ glycine- $\mathrm{NaOH}$ buffer) and $60^{\circ} \mathrm{C}$ (optimal conditions). The absorbance of the soluble fraction was estimated at $280 \mathrm{~nm}$ against the blank. A standard curve was generated using L-tyrosine. One unit of protease activity was defined as the amount of enzyme required to liberate $1 \mu \mathrm{g}$ of tyrosine per min under the experimental conditions.

\section{Microscopic examination}

Phase-contrast microscope (PCM) (AXIOSTAR-plus, ZEISS) was used for morphological characterization of YNDH isolate and Gram stain examination. SEM was performed with JSM 5300 scanning electron microscope (JEOL, USA) at $20 \mathrm{kV}$ in the Centre Laboratory, City of Scientific Research and Technological Applications. 


\section{DNA extraction and PCR for sequencing of 16srRNA PCR product}

Salting out method was applied for the total genomic DNA isolation [17] and then used as a template for polymerase chain reaction (PCR). The 16srRNA-PCR product $(1.5 \mathrm{~kb})$ was amplified by utilizing gene-specific $16 \mathrm{~s}$ degenerate primers. TA cloning for the resulting PCR product was performed using InsTAclone PCR Cloning Kit (Fermentas, USA). Automated DNA sequencing for cloned fragment was carried out using the ABI PRISM model 3730 [18]. The extracted purified plasmid was sequenced using M13pUC forward/reverse (F: 5'GTAAAACGACGGCCAGT-3' and R: 5'-CAGGAA ACAGCTATGAC-3'), and 16srRNA primer and an intermediate forward primer (F: 5' AGCGGCACCT GAAACTGGAT-3').

\section{Alignment and phylogeny}

The obtained 16srRNA gene sequences were assembled using DNA STAR program http://www.dnastar.com and BLAST https://blast.ncbi.nlm.nih.gov/Blast.cgi was used to assess the similarity of the assembled sequences. Multiple sequence alignment, molecular phylogeny was performed using MEGA software version 4.0.2 [19]. Subsequently, the sequence has been deposited in the GenBank under accession number MH894395.

\section{Statistical optimization for production of protease with keratinolytic activity}

The optimization of physicochemical factors for a protease with keratinolytic activity production was carried out in two stages. The first was the screening of physicochemical factors using PBD. The second was the optimization of the most significant factors that control the enzyme production process using Box-Behnken design (BBD).

\section{Plackett-Burman Design (PBD)}

The design was used to select the key factors that significantly influenced the protease activity. PB experimental design consisting of a set of 16 experiments (trials) was used to determine the relative significance of 14 factors (variables) that influenced protease production by YNDH in submerged fermentation. PBD depends on the first-order model $Y=\beta_{0}+\sum \beta_{i} x_{i}$, where in this model, $Y$ represents the response, $\beta_{0}$ is the model intercept, $\beta_{i}$ is the variable estimate, and $x_{i}$ represents the variable. The significance of variables was determined by calculating the $p$ value through standard regression analysis. Table 1 illustrates the factors under investigation as well as the levels of each studied factor in the experimental design, and the measured response (protease activity $\mathrm{U} / \mathrm{ml}$ ). For each factor, a high $(+1)$ and low $(-1)$ concentration was tested. All trials were performed in triplicate (using $50 \mathrm{ml}$ medium in a $250 \mathrm{ml}$ Erlenmeyer flasks), and the average value was calculated for the measured response.

\section{Response surface methodology (RSM) through Box- Behnken Design (BBD)}

RSM was used to optimize the screened components for enhanced protease production using BBD. After estimating the relative significance of independent variables, the most significant three variables were selected for further determination of their optimal level with respect to enzyme activity $(\mathrm{U} / \mathrm{ml})$ as a response. This optimization process involved three main steps: performing the statistically designed experiments, estimating the coefficients of the structured mathematical model, predicting the response, and checking the adequacy of the model [20]. Table 3 represents the design matrix (consisting of 14 trials with two central points), three levels (high, medium, and low) for the selected variables which were denoted by $+1,0$, and -1 , respectively, and the measured response [21]. The created model was applied using the coefficient results of each variable [22]. For three variables, the following second-order polynomial structured model was used:

$$
\begin{aligned}
Y= & \beta_{0}+\beta_{1}\left(X_{1}\right)+\beta_{2}\left(X_{2}\right)+\beta_{3}\left(X_{3}\right)+\beta_{12}\left(X_{1} X_{2}\right) \\
& +\beta_{13}\left(X_{1} X_{3}\right)+\beta_{23}\left(X_{2} X_{3}\right)+\beta_{11}\left(X_{1}\right)^{2} \\
& +\beta_{22}\left(X_{2}\right)^{2}+\beta_{33}\left(X_{3}\right)^{2}
\end{aligned}
$$

where $Y$ is the predicted response; $\beta_{0}$ is the model intercept; $X_{1}, X_{2}$, and $X_{3}$ are the independent variables; $\beta_{1}, \beta_{2}$, and $\beta_{3}$ are linear coefficients; $\beta_{12}, \beta_{13}$, and $\beta_{23}$ are cross-product coefficients; and $\beta_{11}, \beta_{22}$, and $\beta_{33}$ are the quadratic coefficients.

\section{Statistical analysis of data}

The enzyme activity data were subjected to multiple linear regressions using the JMP program to estimate the $t$ values, $p$ values, and confidence levels expressing the $p$ values as a percentage. The significance level ( $p$ value) was determined using the Student $t$ test. The $t$ test for any individual effect allows an evaluation of the probability of finding the observed effect purely by chance. If the probability of the variable under test is sufficiently small, it will be accepted. The confidence level is an expression of the $p$ value in percent. The optimal value of activity was estimated using the JMP program. The simultaneous effects of the three most significant independent factors on each response were visualized using a three-dimensional graph generated by STATISTICA 5.0 software [20]. 


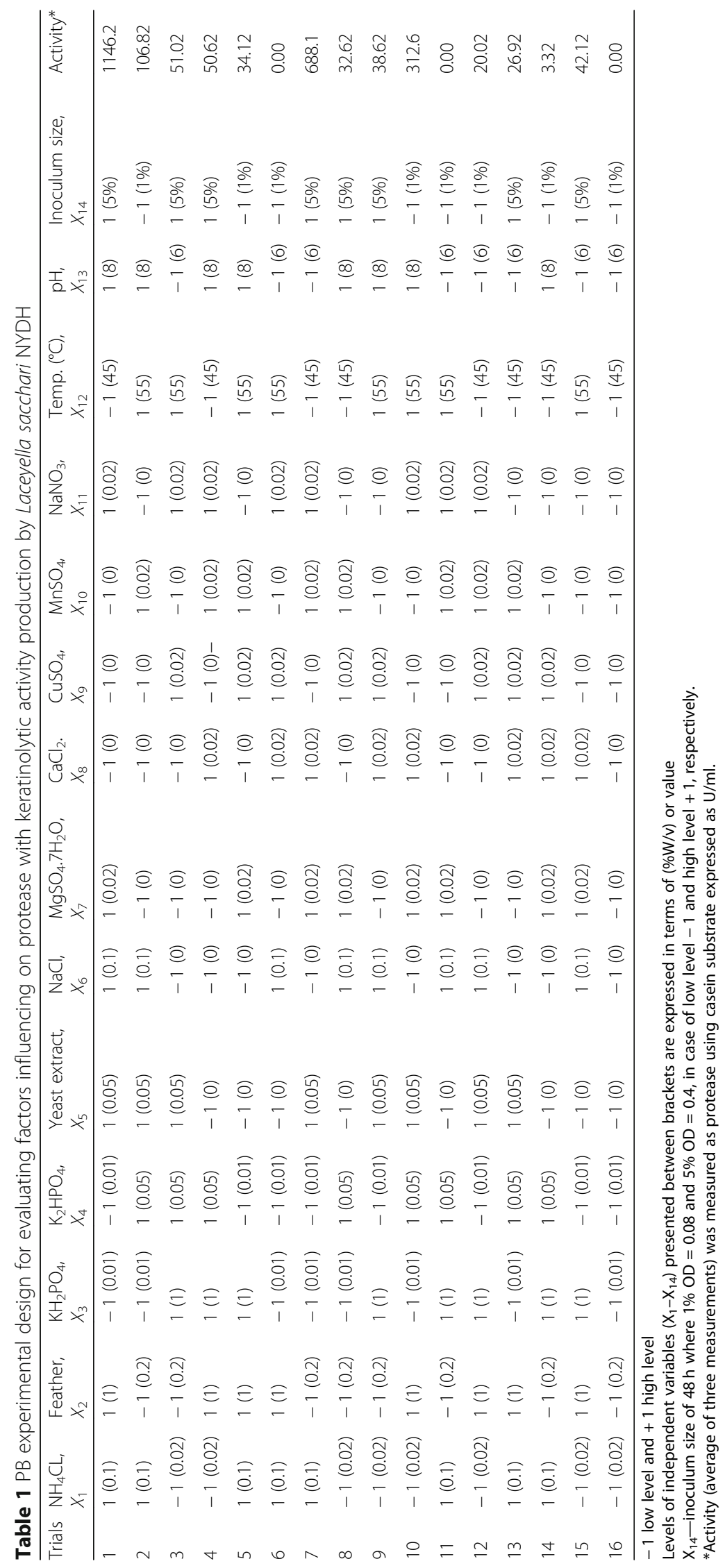


Degradation of synthetic keratin-containing substrate (keratin-azure) by YNDH protease/keratinase

To test the ability of YNDH protease/keratinase to degrade synthetic substrate (keratin-azure), $10 \mathrm{ml}$ of the produced enzyme was added to a flask containing $0.1 \mathrm{~g}$ keratin-azure in $100 \mathrm{mM}$ glycine- $\mathrm{NaOH}$ buffer, $\mathrm{pH} 10$, and then incubated for $1 \mathrm{~h}$, at $60^{\circ} \mathrm{C}$, where the appearance of blue color is considered an indicator of enzyme action.

\section{Degradation of natural keratin-containing substrates by YNDH isolate}

The ability of YNDH isolates to degrade keratin-containing natural substrate (wool, human hair, and nails) was tested individually by replacing the chicken feather, in the optimized medium, with the tested natural inducer at the same concentration (1\%) except the nail which was used at $0.1 \%$. The experiment was carried out in a 250-ml Erlenmeyer flask containing $50 \mathrm{ml}$ optimized medium with the following composition (\% w/v): $\mathrm{NH}_{4} \mathrm{Cl}, 0.08$; feather, 1 ; yeast extract, $0.04 ; \mathrm{MgSO}_{4} .7 \mathrm{H}_{2} \mathrm{O}, 0.02 ; \mathrm{NaNO}_{3}, 0.016 ; \mathrm{KH}_{2} \mathrm{PO}_{4}$, $0.01 ; \mathrm{K}_{2} \mathrm{HPO}_{4}, 0.01 ; \mathrm{pH}, 8$; inoculum size, $5 \%$; and cultivation Temp., $45^{\circ} \mathrm{C}$ for $48 \mathrm{~h} /$ or 15 days. Afterwards, several photographs were taken using SEM to examine the effects of degradation on used natural substrates especially feather and nails.

\section{Dehairing of goat hides by YNDH protease/keratinase}

Fresh goatskin was obtained from a local butcher and incubated in a solution of chloroform and ethanol 90\% (ratio, 2:1) for $2 \mathrm{~h}$ in order to remove lipids and fats [23]. The skin was then washed with Det. and water to remove impurities and dried in an oven at $60^{\circ} \mathrm{C}$ overnight. The skin was kept at $4{ }^{\circ} \mathrm{C}$ until further use. Goatskin pieces $\left(4 \mathrm{~cm}^{2} \times 4 \mathrm{~cm}^{2}\right)$ were incubated in a beaker containing $10 \mathrm{~mL}$ of crude protease/keratinase enzyme then completed to $20 \mathrm{ml}$ glycine- $\mathrm{NaOH}$ buffer $\mathrm{pH} 10$ and the beaker was incubated at $37^{\circ} \mathrm{C}$ for $1 \mathrm{~h}$. Chemical dehairing was performed with $10 \%$ lime and $2 \%$ sodium sulfide for $1 \mathrm{~h}$ at room Temp. Afterwards, several photographs were taken using SEM to examine the effects of bio- and chemical dehairing on the skin surface and hair.

\section{De-staining of blood-stained and chocolate-stained fabric}

Wash performance of the crude protease/keratinase enzyme of YNDH strain was evaluated by applying blood and chocolate stains on white cotton fabrics, using a modified method [24], clean white cotton test fabric pieces $\left(4 \mathrm{~cm}^{2} \times\right.$ $4 \mathrm{~cm}^{2}$ ) were stained with chicken blood and chocolate. The stained pieces were allowed to dry. They were incubated in a beaker containing $10 \mathrm{~mL}$ of crude protease/keratinase enzyme then completed to $20 \mathrm{~mL}$ glycine- $\mathrm{NaOH}$ buffer $\mathrm{pH}$ 10 and the beaker was incubated at $37^{\circ} \mathrm{C}$ for $1 \mathrm{~h}$. A control experiment was conducted under similar conditions, except that no enzyme was added. Stain removal was visually monitored by washing the clothes with tap water.

\section{Results \\ Isolation and screening of protease/keratinase}

In a preliminary screening program for isolation of protease producing micro-organisms, 48 isolates were obtained from soil/ water collected samples. Among, 32 isolates showed protease activity by plate assay using gelatin/casein substrate each at the same isolation conditions ( $\mathrm{pH}$ and Temp.). However, within 32 isolates which showed positive protease activity, only one isolate coded YNDH (isolated from Egyptian El-Minya soil) showed remarkable potency for feather degradation in selective medium ( $\mathrm{pH} 10)$. In order to determine the optimum conditions required for enzyme activity in cell free supernatant, different $\mathrm{pHs}$ and temperatures were tested (data not shown). The maximum enzyme activity $(132,9 \mathrm{U} / \mathrm{ml})$ was obtained under the optima assay conditions ( $\mathrm{pH} 10$ and Temp. $\left.60{ }^{\circ} \mathrm{C}\right)$. On the other hand, the stated optima Temp. and $\mathrm{pH}$ for growth of $\mathrm{YNDH}$ strain ranged $45-55^{\circ} \mathrm{C}$ and $\mathrm{pH} 8-9$ (data not shown).

\section{Morphological/molecular characteristics of the selected YNDH isolate}

The isolate is Gram-positive and formed ball-shaped structures in liquid media. A filamentous growth, tangled hyphae, and spores clearly appear under SEM (Fig. 1). The obtained assembled sequence of 16srRNA was submitted to the BLAST in order to find homologies with other relevant sequences, where it showed 99\% identity to Laceyella sacchari VTT E062990 (ac, EU430566.1). Moreover, the phylogenies of the selected isolate (YNDH) and closely related species was analyzed using the multisequence alignment program and the results confirmed that $\mathrm{YNDH}$ was close to Laceyella sacchari VTT E062990.

\section{Statistical optimization for protease production by multi-} factorial experiment

PBD design (the first approach) was applied to evaluate the relative significance of cultivation variables affecting the production of protease/keratinase enzyme by Laceyella sacchari YNDH strain. Based on the regression analysis shown in Table 2; the regression coefficient of the 14 variables, namely, $\mathrm{NH}_{4} \mathrm{Cl}$, feather substrate, yeast extract, $\mathrm{MgSO}_{4}, \mathrm{NaNO}_{3}, \mathrm{pH}$, and inoculums, had shown a positive effect on protease activity. However, $\mathrm{KH}_{2} \mathrm{PO}_{4}, \mathrm{NaCl}, \mathrm{CaCl}_{2}$, $\mathrm{CuSO}_{4} \mathrm{MnSO}_{4}$, and cultivation Temp. were found out to contribute negatively. The 14 variables were analyzed using a linear multiple regression analysis method and the \% confidence level was calculated on the basis of the confidence level $(\%)=(1-p$ value $) \times 100$. Also, the main effect was calculated basically as a difference between the average measurements of each variable made at a high level $(+1)$ and a low level $(-1)$ (Table 2). 


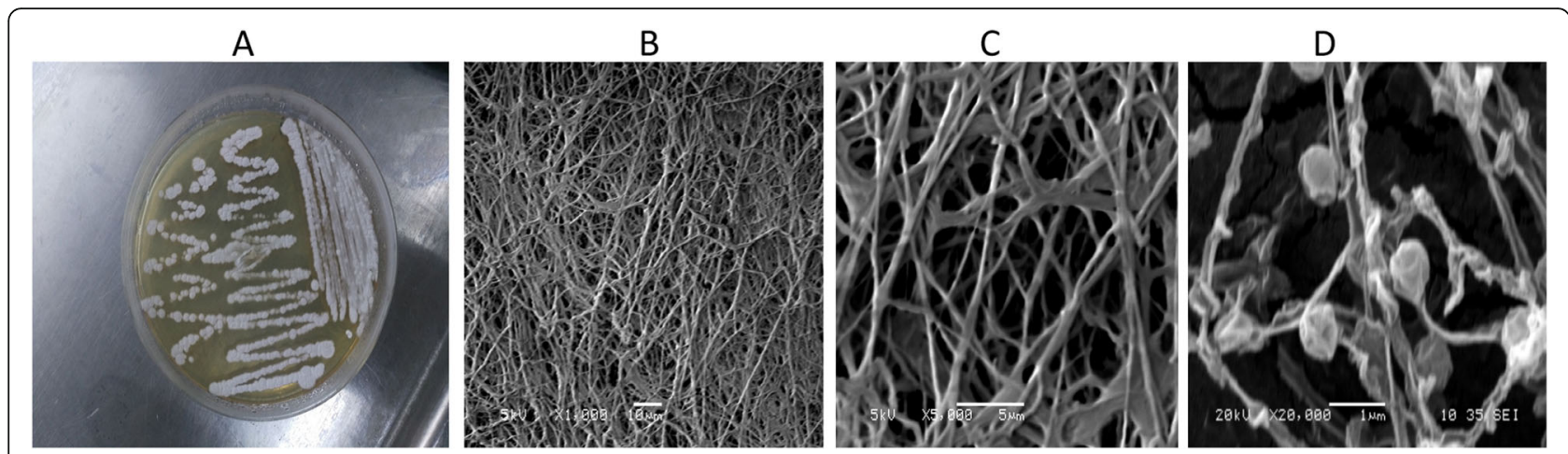

Fig. 1 Morphological characteristics of YNDH isolate, where a typical growth in a solid medium, $\mathbf{b}, \mathbf{c}$ mass of hyphae under phase-contrast microscope at $\times 1$ and $\times 5$ magnification power, respectively, and $\mathbf{d}$ hyphae and spores under SEM at $\times 20$ magnification power

The $p$ value from the ANOVA analysis for each response was determined to analyze the relationship between the variables at $90 \%$ or higher confidence level. The analysis of variance using ANOVA test gives $p=$ 0.0443 , indicates that there is a statistically significant relationship between the variables at $95.57 \%$ confidence level. The $R$-squared statistic indicates that the model as fitted explains $99.9 \%$ of the variability in protease with keratinolytic activity which is the measured response. The polynomial model describing the correlation between the 14 factors and the protease with keratinolytic activity could be presented as follows: $Y=159.56875+$ $104.7924 X_{1}+15.45378 X_{2}-41.188533 X_{3}-84.973947 X_{4}+$ $100.58568 X_{5}-6.27787 X_{6}+81.807678 X_{7}-64.13942 X_{8}-$ $79.145864 X_{9}-77.924948 X_{10}+95.375328 X_{11}-69.07686 X_{12}$ $+80.681649 X_{13}+99.7760828 X_{14}$.
From the statistical analysis, great attention was paid to the selected three variables: $\mathrm{NH}_{4} \mathrm{Cl}$, yeast extract, and $\mathrm{NaNO}_{3}$ which significantly affect the protease with keratinolytic activity production, while they have confidence level $>95 \%$. According to these results, a medium with the following composition (\%w/v): $\mathrm{NH}_{4} \mathrm{Cl}, 0.1$; feather, 1 ; yeast extract, 0.05; $\mathrm{MgSO}_{4}, 0.02 ; \mathrm{NaNO}_{3}, 0.02 ; \mathrm{KH}_{2} \mathrm{PO}_{4}, 0.01$; $\mathrm{K}_{2} \mathrm{HPO}_{4}, 0.01$; inoculum size 5 ; $\mathrm{pH}, 8$; Temp. $45^{\circ} \mathrm{C}$; and incubation time $48 \mathrm{~h}$, with enzyme activity $1124 \mathrm{U} / \mathrm{ml}$, was used as the basic medium for the next design.

BBD (the second approach) was applied in order to reach the optimum response region for protease with keratinolytic activity production in term of activity $(\mathrm{U} / \mathrm{ml})$, the significant independent variables $\left(X_{1} ; \mathrm{NH}_{4} \mathrm{Cl}, X_{2}\right.$; yeast extract, $X_{3} ; \mathrm{NaNO}_{3}$ ) were further explored, and each at three levels (Table 3). The three variables with fourteen

Table 2 Statistical analysis of PBD showing coefficient values, main effect, $t$ and $p$ values, and confidence level \% for each variable affecting protease with keratinolytic activity production

\begin{tabular}{lllllll}
\hline Variables & Coefficients & Main effect & Standard error & $t$ Stat & $p$ value & Confidence level (\%) \\
\hline Intercept & 159.5688 & & 4.62989 & 34.4648 & 0.018466363 & 96.61554 \\
$\mathrm{NH}_{4} \mathrm{Cl}$ & 104.7925 & 209.5849 & 5.57633 & 18.7923 & 0.033844614 & 78.77947 \\
Feather & 15.45379 & 30.90757 & 5.35089 & 2.88807 & 0.212205337 & 91.41578 \\
$\mathrm{KH}_{2} \mathrm{PO}_{4}$ & -41.1885 & -82.37706 & 5.58779 & -7.3711 & 0.085842193 & 95.81786 \\
$\mathrm{~K}_{2} \mathrm{HPO}_{4}$ & -84.9739 & -169.9478 & 5.59022 & -15.200 & 0.04182138 & 96.45754 \\
Yeast extract & 100.5857 & 201.1713 & 5.60285 & 17.9525 & 0.035424603 & 55.49969 \\
$\mathrm{NaCl}$ & -6.27788 & -12.55575 & 5.27715 & -1.1896 & 0.445003112 & 95.72617 \\
$\mathrm{MgSO}_{4} .7 \mathrm{H}{ }_{2} \mathrm{O}$ & 81.80768 & 163.6153 & 5.50027 & 14.8733 & 0.042738313 & 94.55399 \\
$\mathrm{CaCl}_{2}$ & -64.1394 & -128.2788 & 5.50027 & -11.661 & 0.054460083 & 95.76152 \\
$\mathrm{CuSO}_{4}$ & -79.1459 & -158.2917 & 5.27715 & -14.9978 & 0.042384761 & 95.43052 \\
$\mathrm{MnSO}_{4}$ & -77.9249 & -155.817 & 5.60285 & -13.9081 & 0.045694769 & 96.27285 \\
$\mathrm{NaNO}_{3}$ & 95.37533 & 190.7506 & 5.59022 & 17.0610 & 0.0372715 & 94.86142 \\
Temp. & -69.0769 & -138.1537 & 5.58779 & -12.3621 & 0.051385815 & 95.78404 \\
$\mathrm{pH}_{\text {Inoculum }}$ & 80.68165 & 161.3632 & 5.35089 & 15.0781 & 0.042159573 & 96.44573 \\
\hline
\end{tabular}


Table 3 Matrix designed, studied variables, and levels for Laceyella sacchari strain (YNDH) BB factorial experimental design

\begin{tabular}{|c|c|c|c|c|c|c|c|c|c|c|}
\hline Trials & $X_{1}\left(\mathrm{NH}_{4} \mathrm{Cl}\right)$ & $X_{2}$ (yeast extract) & $X_{3}\left(\mathrm{NaNO}_{3}\right)$ & $x_{1} x_{2}$ & $x_{1} x_{3}$ & $x_{2} x_{3}$ & $x_{12}$ & $x_{22}$ & $x_{32}$ & Activity* \\
\hline 1 & $-1(0.08)$ & $-1(0.04)$ & $0(0.026)$ & 1 & 0 & 0 & 1 & 1 & 0 & 1139.2 \\
\hline 2 & $1(0.18)$ & $-1(0.04)$ & $0(0.026)$ & -1 & 0 & 0 & 1 & 1 & 0 & 933.2 \\
\hline 3 & $-1(0.08)$ & $1(0.095)$ & $0(0.026)$ & -1 & 0 & 0 & 1 & 1 & 0 & 999.2 \\
\hline 4 & $1(0.18)$ & $1(0.095)$ & $0(0.026)$ & 1 & 0 & 0 & 1 & 1 & 0 & 977.2 \\
\hline 5 & $-1(0.08)$ & $0(0.065)$ & $-1(0.016)$ & 0 & 1 & 0 & 1 & 0 & 1 & 1002.2 \\
\hline 6 & $1(0.18)$ & $0(0.065)$ & $-1(0.016)$ & 0 & -1 & 0 & 1 & 0 & 1 & 666.2 \\
\hline 7 & $-1(0.08)$ & $0(0.065)$ & $1(0.036)$ & 0 & -1 & 0 & 1 & 0 & 1 & 555.2 \\
\hline 8 & $1(0.18)$ & $0(0.065)$ & $1(0.036)$ & 0 & 1 & 0 & 1 & 0 & 1 & 1061.2 \\
\hline 9 & $0(0.13)$ & $-1(0.04)$ & $-1(0.016)$ & 0 & 0 & 1 & 0 & 1 & 1 & 1033.2 \\
\hline 10 & $0(0.13)$ & $1(0.095)$ & $-1(0.016)$ & 0 & 0 & -1 & 0 & 1 & 1 & 759.2 \\
\hline 11 & $0(0.13)$ & $-1(0.04)$ & $1(0.036)$ & 0 & 0 & -1 & 0 & 1 & 1 & 911.2 \\
\hline 12 & $0(0.13)$ & $1(0.095)$ & $1(0.036)$ & 0 & 0 & 1 & 0 & 1 & 1 & 921.2 \\
\hline 13 & $0(0.13)$ & $0(0.065)$ & $0(0.026)$ & 0 & 0 & 0 & 0 & 0 & 0 & 851.2 \\
\hline 14 & $0(0.13)$ & $0(0.065)$ & $0(0.026)$ & 0 & 0 & 0 & 0 & 0 & 0 & 854.2 \\
\hline
\end{tabular}

Notes: -1 (low level), 0 (middle level), and +1 (high level)

Levels of variables $\left(X_{1}, X_{2}\right.$, and $\left.X_{3}\right)$ presented between brackets are expressed in terms of $(\% \mathrm{w} / \mathrm{v})$

*Activity (average of three measurements) was measured as protease using casein substrate and expressed as $\mathrm{U} / \mathrm{ml}$

trials were analyzed using a linear multiple regression analysis method, and the percentage confidence levels (\%) were calculated as mentioned previously. The value of the determination coefficient $R^{2}=0.925$ for protease with keratinolytic activity, being a measure of fit of the model, indicates that about $7.5 \%$ of the total variations are not explained by protease with keratinolytic activity. Presenting experimental results in the form of surface plots shows that higher levels of protease with keratinolytic activity were attained with lower levels of $\mathrm{NH}_{4} \mathrm{Cl}$, yeast extract, and $\mathrm{NaNO}_{3}$ (Fig. 2). For predicting the optimal point of variable, within experimental constrains, a second-order polynomial function was fitted to the experimental results (non-linear optimization algorithm: $Y=852.7-7.249 X_{1}$ $-45 X_{2}-1.4999 X_{3}+46 X_{1} X_{2}+210.5 X_{1} X_{3}+71 X_{2} X_{3}+$ $37.25 X_{1}^{2}+122.25 X_{2}^{2}-68.749 X_{3}^{2}$ ).

The optimal levels of the three studied variables, as obtained from the maximum point of the polynomial model, were found to be $(\% \mathrm{w} / \mathrm{v}) \mathrm{NH}_{4} \mathrm{Cl}, 0.08$; yeast extract, 0.04; and $\mathrm{NaNO}_{3}, 0.016$; with prediction calculated enzyme activity equal to $1324.7 \mathrm{U} / \mathrm{ml}$. Ultimately, in order to determine the accuracy of the quadratic polynomial, a verification experiment was carried out under predicted optimal conditions monitoring enzyme activity in the optimized medium. To prove the accuracy of the model, the \% accuracy was calculated from the following formula: Accuracy of the model $=[Y$ Experiment $/ Y$ Calculated] $\times 100$.

The bench-scale experiments show that the $Y$ value is $1330.2 \mathrm{U} / \mathrm{ml}$. The calculated model accuracy was $100.4 \%$. In this study, a statistical methodology, a combination of $\mathrm{PB}$ and $\mathrm{BB}$ designs, showed to be effective and reliable on selecting the statistically significant factors and finding the optimal concentrations of those factors. Accordingly, the following medium composition is expected to be near the optimum $(\% \mathrm{w} / \mathrm{v}): \mathrm{NH}_{4} \mathrm{Cl}, 0.08$; feather, 1 ; yeast extract, $0.04 ; \mathrm{MgSO}_{4} .7 \mathrm{H}_{2} \mathrm{O}, 0.02 ; \mathrm{NaNO}_{3}, 0.016$; $\mathrm{KH}_{2} \mathrm{PO}_{4}, 0.01 ; \mathrm{K}_{2} \mathrm{HPO}_{4}, 0.01 ; \mathrm{pH}, 8$; inoculum size, 5\%; and incubation Temp. $45^{\circ} \mathrm{C}$ for $48 \mathrm{~h}$ incubation time.

\section{Utilization/degradation of different keratin-containing substrates and SEM examination}

In this experiment, we tested the ability of Laceyella sacchari YNDH to grow on different substrates (feather, sheep wool, human hair, and human nails), where the degradation of the tested substrate can be easily recognized by eye. Complete degradation of feather and a partial for wool and hair was noticed after 48-h incubation (Fig. 3a-c). A longer time was needed for nail degradation (15 days) as shown in Fig. 3d. Also, by testing the effect of keratinase enzyme produced from YNDH on keratin-azure, the enzyme showed positive reaction indicated by releasing a blue color of azure dye into the buffer (Fig. 3e).

Electron micrographs for degrading feathers and nails were screened using SEM against control. A smooth surface for untreated feather (control) was noticed, while complete disappearance of feather barbs and high degradation of feather rachis during the course of fermentation $(48 \mathrm{~h})$ for treated feather were observed (Fig. 3). No degradation for untreated nail (control) under SEM was noticed; however, a high degree of degradation of the nail after 15 days of fermentation was recognized and intensive accumulation of spores on the surface of the 


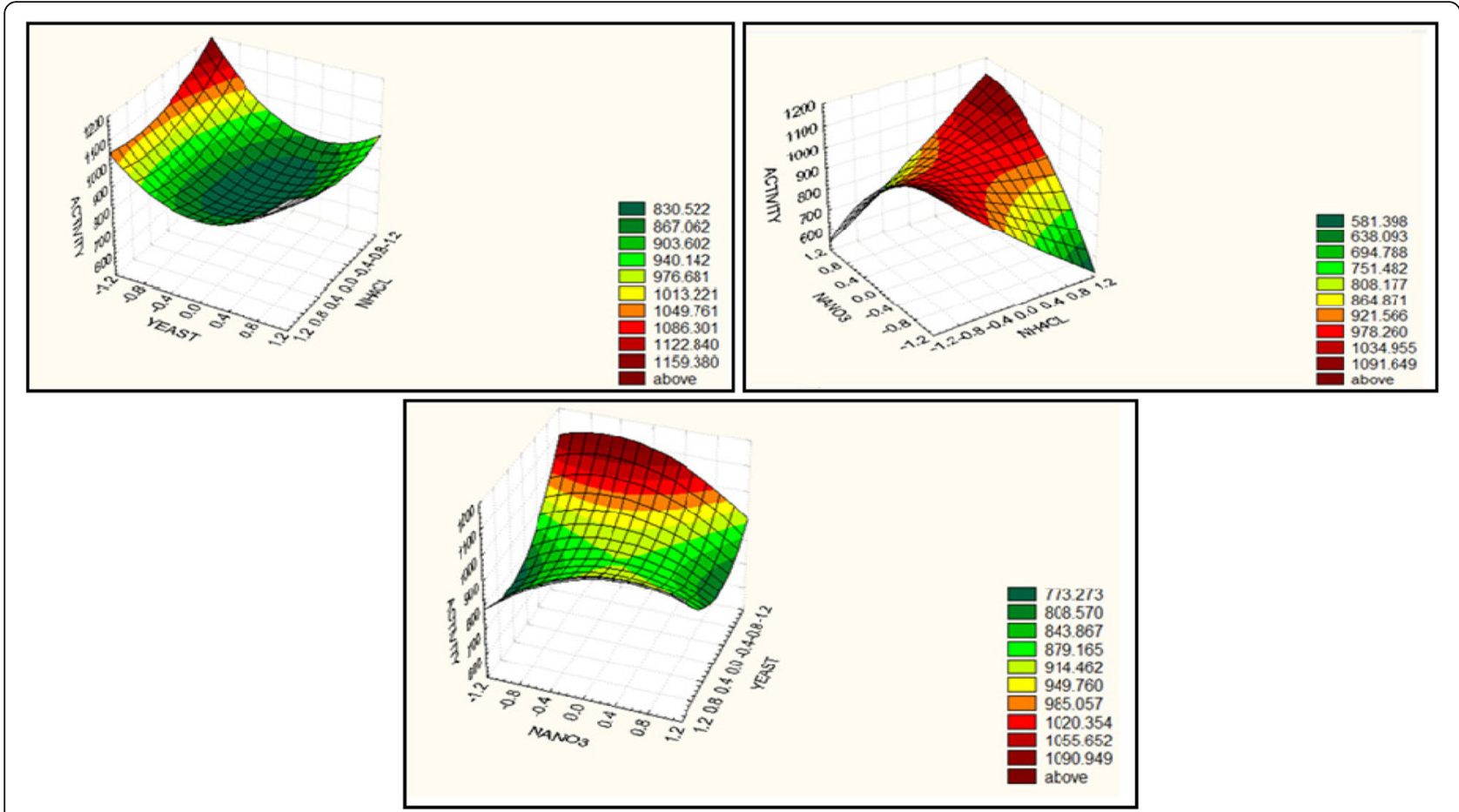

Fig. 2 Three-dimensional response surface representing protease with keratinolytic activity yield (U/ml) from Laceyella sacchari strain (YNDH) as affected by culture conditions
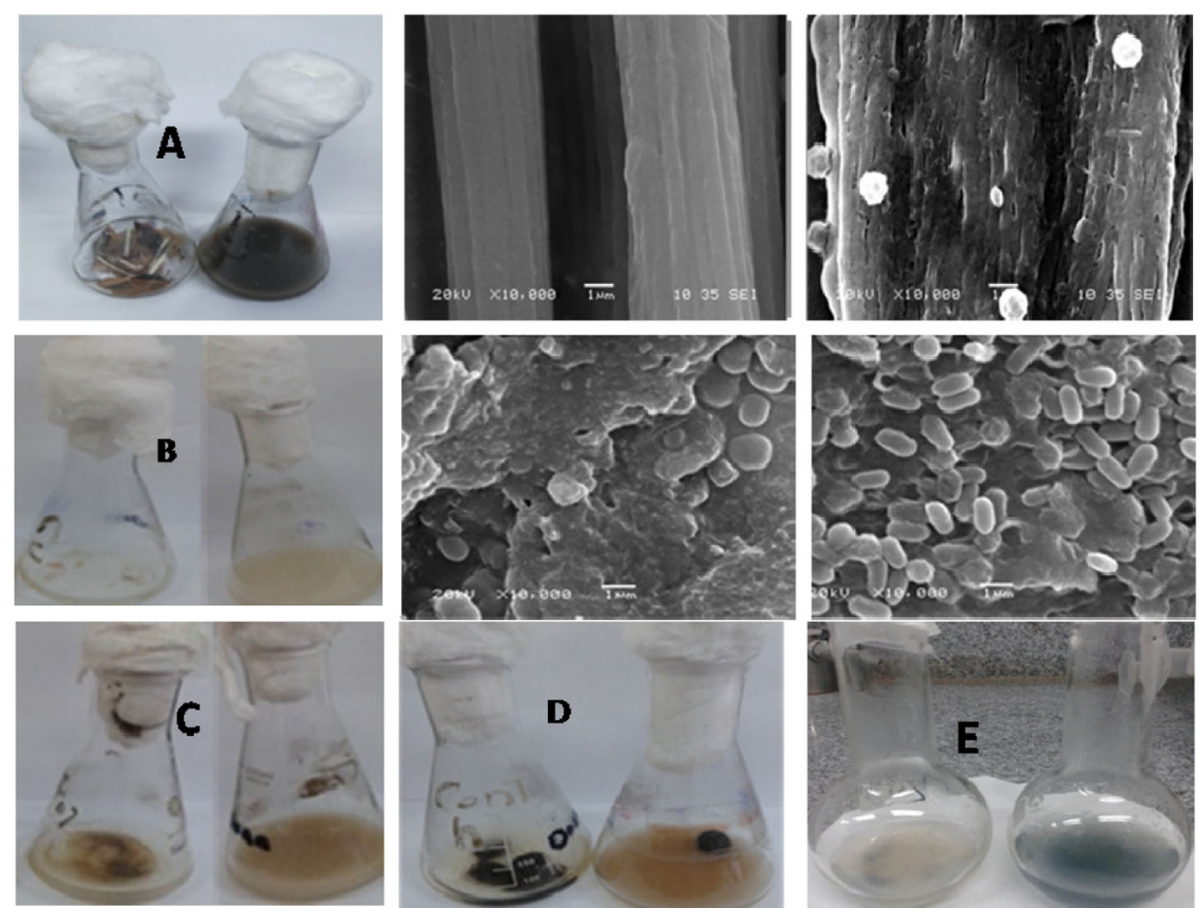

Fig. 3 Growth of Laceyella sacchari YNDH on feather (a), human nails (b), and relative SEM examination at $\times 10$ magnification power for control (left) and sample (right). Growth of Laceyella sacchari YNDH on wool (c), human hair (d), and synthetic substrate keratin-azure (e), the control at left and the sample at right 
degraded nail appeared at high-magnification power examination (Fig. 3).

De-staining of blood-stained and chocolate-stained fabric In order to evaluate the performance of crude enzyme in terms of ability to remove harsh stains, namely those caused by chicken blood or chocolate, several pieces of stained cotton cloth were incubated at different conditions (Fig. 4). The findings from these assays revealed that the blood and chocolate stain removal levels, achieved with the use of crude enzyme alone, were more effective than the ones obtained with Det. or water alone.

\section{Dehairing of goat hides}

The dehairing efficiency for the keratinase enzyme produced from YNDH was tested and examined microscopically. The degree of leather quality generated by the keratinase-based processing was also compared with the conventional chemical treatment of dehairing. The hide surfaces were treated using enzymatic and sulfide lime and the released hairs were examined by scanning electron microscope. The conventional method caused complete degradation of hair and the deposition of the chemicals on the skin surface. In contrast, enzymatictreated samples caused no degradation of hair and the smooth surface was maintained (Fig. 5a-f).

\section{Discussion}

Thermoactinomyces is known for its resistance to extreme environmental conditions and its ability to digest a wide range of hard-to-degrade compounds. Keratinolytic activity has been described for some thermophiles, such as Thermoactinomyces spp. [25]. However, this study is considered the first work to report that Laceyella sacchari $\mathrm{YNDH}$ is a producer of protease/keratinase enzyme, so this strain is distinct in concern its dual activities. Because microbial keratinases are inducible enzymes and are substrate specific [26], various keratinous materials like chicken feathers, feather meal, wool, bovine hair, and human foot skin have been used as an inducer of keratinase [27]. A sequential optimization strategy was implemented in order to improve protease/keratinase production by a locally isolated Laceyella sacchari YNDH through two steps (PB and $\mathrm{BB}$ ). Normally, when screening the variables influencing the development of certain secondary metabolites, it is very essential to test as many variables as possible and to recognize their importance [14]. PB design provides a nice, quick screening process and mathematically calculating the significance of a large number of variables in one experiment that saves time and keeps convincing data about each factor. Although interaction is not included in this model, examining the interaction between these large numbers of factors is not of first priority in the screening program. Only the most efficient and beneficial factors would be chosen from the totality of the variables for further optimization, while those showing a high negative effect on the bioprocess may be dropped in all further experiments. In this study, PB results showed a wide variation from 0 up to $1146.2 \mathrm{U} / \mathrm{ml}$ of protease with keratinolytic activity. This variation reflects the importance of medium optimization to attain higher productivity. According to the analysis of the regression coefficients, $t$ test, and $p$ value for the 14 variables, $\mathrm{NH}_{4} \mathrm{Cl}$, yeast extract, and $\mathrm{NaNO}_{3}$ were the most significant variables increasing the protease with keratinolytic activity production with a $p$ value of 0.0338 , 0.03542 , and 0.03547 , respectively, whereas $\mathrm{K}_{2} \mathrm{HPO}_{4}$, $\mathrm{MnSO}_{4}, \mathrm{CuSO}_{4}$, and $\mathrm{CaCl}_{2}$ were the most significant variables decreasing the protease with keratinolytic activity production with a $p$ value of $0.0418,0.0456,0.0423$, and 0.054 , respectively. This is in agreement with [28, 29], where the yeast extract was found out to exert a positive effect, while $\mathrm{CaCO}_{3}$ and, $\mathrm{K}_{2} \mathrm{HPO}_{4}$ had a negative effect on enzyme production by Amycolatopsis sp. strain MBRL 40. Additionally, $\mathrm{pH}$ showed a significant positive effect on enzyme production while Temp. showed a high negative effect. In general, physical factors such as the

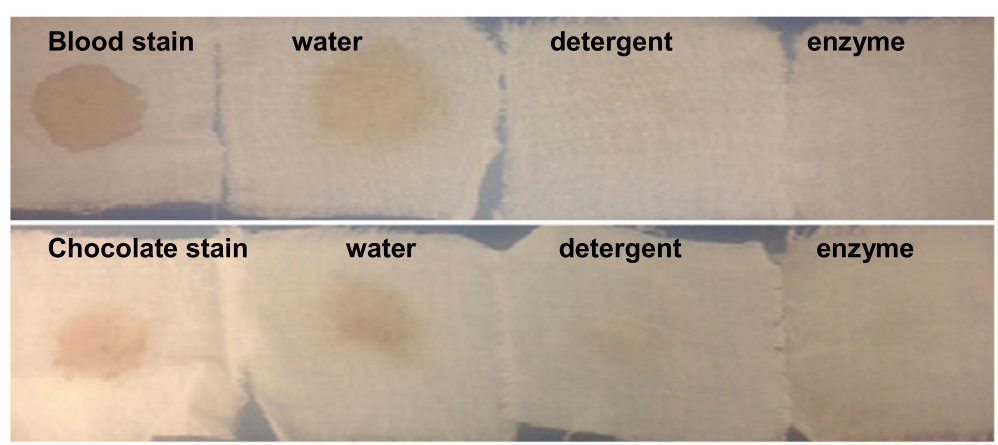

Fig. 4 Washing performance test for crude protease/keratinase YNDH in contrast to detergent and water. Stained cloth pieces with blood or chocolate in the left (control: untreated stained cloth pieces). Stained cloth pieces washed with distilled water, Det. (7 mg/ml), and crude enzyme equivalent $(20 \mathrm{U} / \mathrm{ml})$ 

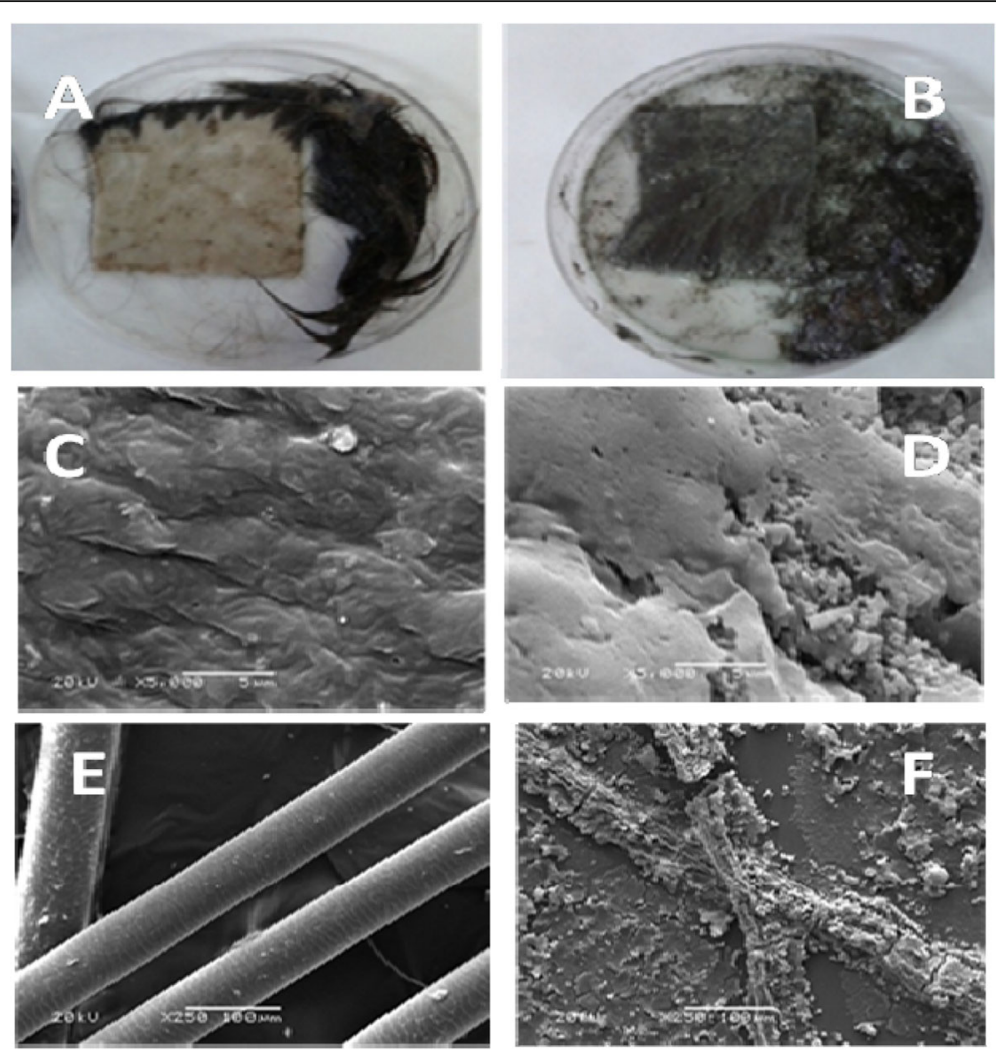

Fig. 5 Dehairing efficiency of crude protease/ keratinase $(\mathbf{a})$ and lime-sulfide $(\mathbf{b})$. SEM examination $(\times 40)$ for skin surface $(\mathbf{c}$, $\mathbf{d})$ and released hairs $(\mathbf{e}, \mathbf{f})$ upon using crude protease/keratinase and lime-sulfide mixture, respectively

optimal Temp. and $\mathrm{pH}$ values varied in other researches, depending on the species producing the enzyme [3034]. One of the advantages of the PBD is that it allows operators to rank the effect of different variables on the measured response independently of the nature of the factor (either nutritional or physical) or the nature of the signs (positive or negative). The second step in the optimization of keratinase production is medium components using statistical methods such as RSM which improve enzyme production. In order to approach the optimum response region of the protease with keratinolytic activity, the significant independent variables $\left(\mathrm{NH}_{4} \mathrm{Cl}\right.$, yeast extract, and $\left.\mathrm{NaNO}_{3}\right)$ were further studied, each at three levels: $-1,0$ and +1 . Presenting experimental results in the form of surface plots showed that lower levels of yeast extract, $\mathrm{NH}_{4} \mathrm{Cl}$, and $\mathrm{NaNO}_{3}$ support high enzyme production yields/activity. The highest effective interaction was noticed by using the low value of both $\mathrm{NH}_{4} \mathrm{Cl}$ and $\mathrm{NaNO}_{3}$. In this experiment, the value of $R^{2}$ was 0.925 for protease with keratinolytic activity. This value indicates a high degree of correlation between the experimental and the predicted values. The optimal conditions, realized from the optimization experiment, were verified experimentally and compared to the predicted optimum of the model. The estimated protease with keratinolytic activity was $1330 \mathrm{U} / \mathrm{ml}$, and the predicted value from the polynomial model was $1324.7 \mathrm{U} /$ $\mathrm{ml}$. This high degree of accuracy (100.4\%) is evidence of the model validation under optimal conditions. Additionally, the value of enzyme activity in the optimized medium was 10 -fold the basal conditions. This reflected the necessity and value of the optimization process. Our work agrees with $[35,36]$, where the RSM is a widely accepted modern statistical approach for the optimization of the experimental conditions and the solution of the analysis problems, in which a response is greatly influenced by several variables for the production of industrially important biomolecules. RSM helps to identify the successful factors to study interactions, to calculate the optimum level of the variables, and to ensure the maximum production in a fixed number of experiments [36]. Accordingly, the usage of cost-effective growth medium for increasing the yield of proteases with respect to their industrial requirements is highly appreciable from the commercial point of view. In fact, the low-cost substrates were screened for the maximum production of keratinase. Some cost-effective substrates such as soybean meal have been successfully used by Vidyasagar et al. [37]. In conclusion, Laceyella sacchari YNDH is a good producer for protease with keratinolytic activity 
using feathers as the sole source of carbon/nitrogen. In the present work, we examined the effect of Laceyella sacchari YNDH on the degradation of feathers, sheep wool, human hair, and human nails, which were significantly degraded. These findings are in agreement with [38], who reported that Keratinases are produced by several bacteria, fungi, and actinomycetes. Due to the ability of Laceyella sacchari strain YNDH to significantly degrade/hydrolyze keratin in nails, this opens the way for using YNDH keratinase in pharmaceutical enhancement of the nail treatment. In our work, the findings from Wash performance analysis assays revealed that the blood and chocolate stain removal levels, achieved with the use of crude protease with keratinolytic activity of YNDH alone, were more effective than the ones obtained with Det. alone. In fact, our enzyme facilitated the release of proteinaceous materials in a much easier way than Det. alone. In fact, a similar study has previously reported the usefulness of alkaline protease, namely SAPB, in the blood and chocolate stain removal from cotton cloth [39]. Leather processing industries generate a lot of toxic pollutants, such as sulfide and chromate, which are found to be detrimental to the environment. Therefore, dehairing, using a microbial keratinase, is considered an easy alternative [40]. There are many reports of dehairing of goat/bovine skin, employing purified/semi-purified keratinases [41-43]. In the present study, the crude protease with keratinolytic activity from Laceyella sacchari strain YNDH completely dehaired goat hides without affecting the skin quality. In contrast, chemical dehairing had shown complete inability to remove of the hair from the goatskin, because parts of the hair were still seen on the skin.

\section{Conclusion}

Proteases are the most widely exploited enzymes in industry. Thermo-alkaliphilic proteases with keratinolytic activity have a wide range of biotechnological applications due to their ability to act at various harsh conditions and degrade a wide range of keratin-containing natural substrates. Thus, this study has focused on the production, optimization, and multifunctional application of keratin-degrading protease enzyme produced by an Egyptian local isolate Laceyella sacchari strain YNDH. The theme chosen for the research can be exploited in many industries and various applications.

\footnotetext{
Abbreviations

LB: Luria-Bertani; DNA: Deoxyribonucleic acid; RNA: Ribonucleic acid; PCR: Polymerase chain reaction; OVAT: One variable at a time; SEM: Scanning electron microscope; BBD: Box-Behnken design; RSM: Response surface design; PBD: Plackett-Burman Design; Det.: Detergent; Temp.: Temperature; PCM: Phase-contrast microscope
}

\section{Acknowledgements}

The authors are extremely grateful to the City of Scientific Research and Technological Applications (SRTA-City), Alexandria, Egypt, for providing all facilities to complete this work.

\section{Authors' contributions}

DAG performed the experimental part of the work and wrote the main manuscript text. NAS contributed to isolate identification, designed the experiments, and revised the manuscript. ARB prepared the figures of the work. NMAM performed the analysis part. YRAF accomplished the interpretation of the data and substantively revised the manuscript. All authors read and approved the manuscript

\section{Funding}

The authors would like to acknowledge the City of Scientific Research \& Technological Applications (SRTA-City) and the Science \& Technology Development Funds (STDF) for their funding of the present work which is located within the frame of grant number 247.

\section{Availability of data and materials}

All data generated or analyzed during this study are included in this published article.

\section{Ethics approval and consent to participate}

This article does not contain any studies involving animals or human participants performed by any of the authors

\section{Consent for publication}

Not applicable

\section{Competing interests}

The authors declare that they have no competing interests.

\section{Author details}

${ }^{1}$ Bioprocess Development Department, Genetic Engineering and Biotechnology Research Institute (GEBRI), City of Scientific Research and Technological Applications (SRTA-City), New Burg El-Arab City, Universities and Research Institutes Zone, Alexandria Post 21934, Egypt. ${ }^{2}$ Biochemistry Department, Faculty of Science, Alexandria, Egypt.

Received: 15 March 2020 Accepted: 4 June 2020

Published online: 02 July 2020

\section{References}

1. Hassan MA, Haroun BM, Amara AA, Serour EA (2013) Production and characterization of keratinolytic protease from new wool-degrading Bacillus species isolated from Egyptian ecosystem. BioMed Res Int doi. https://doi. org/10.1155/2013/175012

2. Lo WH, Too JR, Wu IY (2012) Production of keratinolytic enzyme by an indigenous feather-degrading strain Bacillus cereus Wu2. J Biosci Bioeng 114:640-647

3. Onifade AA, Al-Sane NA, Al-Musallam AA, Al-Zarban S (1998) A review: potentials for biotechnological applications of keratin-degrading microorganisms and their enzymes for nutritional improvement of feathers and other keratins as livestock feed resources. Bioresour Technol 66:1-11

4. Gupta R, Ramnani P (2006) Microbial keratinases and their prospective applications: an overview. Appl Microbiol Biotechnol 70:21-33

5. Dalev P, Ivanov I, Liubomirova A (1997) Enzymic modification of feather keratin hydrolysates with lysine aimed at increasing the biological value. J Sci Food Agric 73:242-244

6. Cai CG, Lou BG, Zheng XD (2008) Keratinase production and keratin degradation by a mutant strain of Bacillus subtilis. J Zhejiang Univ Sci B 9: 60-67

7. Matsui T, Yamada Y, Mitsuya H, Shigeri Y, Yoshida Y, Saito Y, Matsui H, Watanabe K (2009) Sustainable and practical degradation of intact chicken feathers by cultivating a newly isolated thermophilic Meiothermus ruber H328. Appl Microbiol Biotechnol 82:941-950

8. Papadopoulos MC, El Boushy AR, Roodbeen AE, Ketelaars EH (1986) Effects of processing time and moisture content on amino acid composition and nitrogen characteristics of feather meal. Anim Feed Sci Technol 14:279-290

9. Joo H, Chang C (2005) Production of protease from a new alkalophilic Bacillus sp. I.312 grown on soya-bean meal: optimization and some properties. Process Biochem 40:1263-1270

10. Box GE, Behnken DW (1960) Some new three level designs for the study of quantitative variables. Technometrics 2:455-475 
11. Liu C, Liu Y, Liao W, Wen Z, Chen S (2003) Application of statistically based experimental designs for the optimization of nisin production from whey. Biotechnol Lett 877- 882.

12. Abdel-Fattah YR (2002) Optimization of thermostable lipase from a thermophilic Geobacillus sp. using Box-Behnken experimental design. Biotechnol Lett 1217-1222.

13. Abdel-Fattah YR, Olama ZA (2002) L-asparaginase production by Pseudomonas aeruginosa in solid-state culture: evaluation and optimization of culture conditions using factorial designs. Process Biochem 38:115-122

14. Abdel-Fattah YR, El-Enshasy HA, Soliman NA, El-Gendi H (2008) Bioprocess development for production of alkaline protease by Bacillus pseudofirmus Mn6 through statistical experimental designs. J Microbiol Biotechnol 19: 378-386

15. Clarke SKK (1953) A simplified plate method for detecting gelatin-liquefying bacteria. J Clinical Pathology 246-248.

16. Kembhavi AA, Kulkarni A (1993) Pant A Salt-tolerant and thermostable alkaline protease from Bacillus subtilis NCIM No. 64. Appl Biochem Biotechnol 38:83-92

17. Anisha GS, Sukumaran RK, Prema P (2008) Statistical optimization of agalactosidase production in submerged fermentation by Streptomyces griseoloalbus using response surface methodology. Food Technol Biotechnol 46:171-177

18. Sanger F, Nicklen S, Coulson AR (1997) DNA sequencing with chain terminating inhibitors. Proc Natl Acad Sci 74:5463-5467

19. Tamura K, Dudley J, Nei M, Kumar S (2007) MEGA4: molecular evolutionary genetics analysis (MEGA) software version 4.0. Mol Biol Evol 24:1596-1599

20. Abdel-Fattah YR, Soliman NA, Yousef SM, El-Helow ER (2012) Application of experimental designs to optimize medium composition for production of thermostable lipase/esterase by Geobacillus thermodenitrificans AZ1. JGEB 10: 193-200

21. Abdel-Fattah YR, El Enshasy H, Anwar M, Omar H, Abolmagd E, Zahra RA (2007) Application of factorial experimental designs for optimization of cyclosporin a production by Tolypocladium inflatum in submerged culture. $J$ Microbiol Biotechnol 17:1930-1936

22. Amara A, Salem SR (2010) Logical and experimental design for phenol degradation using immobilized Acinetobacter sp. Culture. IIUM Engineering Journal 11:89-104

23. Verma A, Pal HS, Singh R, Agarwal S (2011) Potential of alkaline protease isolated from Thermoactinomyces sp. RM4 as an alternative to conventional chemicals in leather industry dehairing process. Int J Agric Environ Biotechnol 4:173-178

24. Kumar D, Bhalla TC (2004) Bacillus sp. APR-4 protease as a laundry additive. Indian J Biotechnol 3:563-567

25. Gousterova A, Braikova D, Goshev I, Christov P, Tishinov K, Vasileva-Tonkova E, Haertle T, Nedkov P (2005) Degradation of keratin and collagen containing wastes by newly isolated thermoactinomycetes or by alkaline hydrolysis. Lett Appl Microbiol 40:335-340

26. Cheng SW, Hu HM, Shen-Hu SW, Takagi H, Asano M, Tsai YC (1995) Production and characterization of keratinase of a feather-degrading Bacillus licheniformis PWD-1. Biosci Biotechnol Biochem 59:2239-2243

27. De T, Richter MF, Chagas JR, Henriques JA, Termignoni C (2002) Purification and characterization of an alkaline serine endopeptidase from a featherdegrading Xanthomonas maltophilia strain. Can J Microbiol 48:342-348

28. Kainoor PS, Naik GR (2010) Production and characterization of feather degrading keratinase from Bacillus sp. JB 99. Indian J.Biotechnol 9:384-390

29. $\mathrm{Ni} \mathrm{H}$, Chen QH, Chen F, Fu ML, Dong YC, Cai HN (2011) Improved keratinase production for feather degradation by Bacillus licheniformis ZJUEL31410 in submerged cultivation. Afr J Biotechnol 10:7236-7244

30. Denizci A, Kazan D, Abeln E, Erarslan A (2004) Newly isolated Bacillus clausii GMBAE 42: an alkaline protease producer capable to grow under highly alkaline conditions. J Appl Microbiol 96:320-327

31. Patel RK, Dodia MS, Joshi RH, Singh SP (2006) Production of extracellular halo-alkaline protease from a newly isolated haloalkaliphilic Bacillus sp. isolated from seawater in Western India. World J Microbiol Biotechnol 22: 375-382

32. Tari C, Genckal H, Tokatlı F (2006) Optimization of a growth medium using a statistical approach for the production of an alkaline protease from a newly isolated Bacillus sp. L21. Process Biochem 41:659-665

33. Falahatpishe H, Jalali M, Badami N, Mardani N, Khosravi-Darani K (2007) Production and purification of a protease from an alkalophilic Bacillus sp. 25 strain isolated from soil. Iran J Biotechnol 5:110-113
34. Sharan A, Darmwal NS (2007) Improved production of alkaline protease from a mutant of alkalophilic Bacillus pantotheneticus using molasses as a substrate. Bioresour Technol 98:881-885

35. Senthilkumar SR, Ashokkumar B, Raj KC, Gunasekaran P (2005) Optimization of medium composition for alkali-stable xylanase production by Aspergillus fischeri Fxn1 in solid-state fermentation using central composite rotary design. Bioresour Technol 96:1380-1386

36. Zhu Z, Zhang G, Luo Y, Ran W, Shen Q (2012) Production of lipopeptides by Bacillus amyloliquefaciens XZ-173 in solid state fermentation using soybean flour and rice straw as the substrate. Bioresour Technol 112:254-260

37. Vidyasagar M, Prakash SB, Sreeramulu K (2006) Optimization of culture conditions for the production of haloalkaliphilic thermostable protease from an extremely halophilic archaeon Halogeometricum sp. TSS101. Lett Appl Microbiol 43:385-391

38. Selvam K (2012) Biochemical and molecular characterization of microbial keratinase and its remarkable applications. Int J Pharm Biol Arch 3:267-275

39. Jaouadi B, Abdelmalek B, Jaouadi NZ, Bejar S (2011) The bioengineering and industrial applications of bacterial alkaline proteases: the case of SAPB and KERAB. INTECH Open Access Publisher 20:445-466

40. Chaturvedi V, Bhange K, Bhatt R, Verma P (2014) Production of kertinases using chicken feathers as substrate by a novel multifunctional strain of Pseudomonas stutzeri and its dehairing application. Biocata Agricult Biotechnol 3:167-174

41. Prakash P, Jayalakshmi SK, Sreeramulu K (2010) Production of keratinase by free and immobilized cells of Bacillus halodurans strain PPKS-2: partial characterization and its application in feather degradation and dehairing of the goat skin. Appl Biochem Biotechnol 160:1909-1920

42. Shrinivas D, Naik GR (2011) Characterization of alkaline thermostable keratinolytic protease from thermoalkalophilic Bacillus halodurans JB 99 exhibiting dehairing activity. Int Biodeterior Biodegradation 65:29-35

43. Paul T, Das A, Mandal A, Jana A, Maity C, Adak A, Halder SK, Das Mohapatra PK, Pati BR, Mondal KC (2014) Effective dehairing properties of keratinase from Paenibacillus woosongensis TKB2 obtained under solid state fermentation. Waste and Biomass Valorization 5:97-107

\section{Publisher's Note}

Springer Nature remains neutral with regard to jurisdictional claims in published maps and institutional affiliations.

\section{Submit your manuscript to a SpringerOpen ${ }^{\circ}$ journal and benefit from:}

- Convenient online submission

- Rigorous peer review

- Open access: articles freely available online

High visibility within the field

- Retaining the copyright to your article

Submit your next manuscript at $>$ springeropen.com 